\title{
A Survey on Types of Injuries in Indonesian Recreational Badminton Players
}

\author{
Tri Hadi Karyono ${ }^{1, *}$, Oce Wiriawan ${ }^{2}$, Hari Setijono ${ }^{2}$ Ibrahim $^{3}$, Ramdan Pelana ${ }^{4}$, Sofyan Hanif ${ }^{4}$, \\ Bagus Winata ${ }^{5}$ \\ ${ }^{1}$ Faculty of Sports Science, Universitas Negeri Yogyakarta, Indonesia \\ ${ }^{2}$ Faculty of Sports Science, Universitas Negeri Surabaya, Indonesia \\ ${ }^{3}$ Faculty of Sports Science, Universitas Negeri Medan, Indonesia \\ ${ }^{4}$ Faculty of Sports Science, Universitas Negeri Jakarta, Indonesia \\ ${ }^{5}$ Sports Science Department, Institut Teknologi Bandung, Indonesia
}

Received August 24, 2021; Revised January 10, 2022; Accepted February 8, 2022

\section{Cite This Paper in the following Citation Styles}

(a): [1] Tri Hadi Karyono, Oce Wiriawan, Hari Setijono, Ibrahim, Ramdan Pelana, Sofyan Hanif, Bagus Winata, "A Survey on Types of Injuries in Indonesian Recreational Badminton Players," International Journal of Human Movement and Sports Sciences, Vol. 10, No. 1, pp. 49 - 53, 2022. DOI: 10.13189/saj.2022.100108.

(b): Tri Hadi Karyono, Oce Wiriawan, Hari Setijono, Ibrahim, Ramdan Pelana, Sofyan Hanif, Bagus Winata (2022). A Survey on Types of Injuries in Indonesian Recreational Badminton Players. International Journal of Human Movement and Sports Sciences, 10(1), 49 - 53. DOI: 10.13189/saj.2022.100108.

Copyright $\mathrm{C} 2022$ by authors, all rights reserved. Authors agree that this article remains permanently open access under the terms of the Creative Commons Attribution License 4.0 International License

\begin{abstract}
The purpose of this study was to find out and describe the types of injuries sustained by recreational badminton players in Indonesia. In this descriptive study, conducted by interview, we evaluated recreational male badminton players $(\mathrm{n}=80)$ at Rawamangun Jakarta Sports Center. The focus of the interview questions was divided into 2 sessions, namely the general session and the main interview session. The general session asks about anthropometry data, years and frequency of playing badminton, medical history, and sports activities, while the main interview session contains the causes of injury, anatomical injury, and frequency of injury in one year. This study showed that the older the participants are, the less frequently they play badminton (41-50 years $=2.2 \pm$ 1.1 vs $31-40$ years $=2.9 \pm 1.1$ vs $21-30$ years $=3.1 \pm 0.8$ ). Acute injuries predominated in the age range of 21-30 years $(83 \%)$ and $31-40$ years (53\%). Meanwhile, at the age of 41-50 years, overuse injury is the dominant injury compared to acute injury ( $83 \%$ vs $17 \%)$. In terms of anatomical injuries, $74 \%$ of 80 participants had lower limb injuries. Regarding the cause of injury, $52.5 \%$ of all 80 participants chose inadequate warm-up as the cause of injury. This study shows that as people get older, the risk of injury in recreational badminton players in Indonesia increases. Inadequate warm-up is a common cause of injury risk for all ages, and the lower limb is the part of the
\end{abstract}

body that is most often injured.

Keywords Epidemiology, Incidence, Acute Injuries, Overuse Injuries

\section{Introduction}

Across the world, badminton is currently experiencing fast and significant development and growth, with 200 million people playing the sport worldwide [1]. The growing interest in badminton is directly proportional to the interest of sports researchers of measuring the risk of injury and the impact of injury when playing this sport [2-4]. It is noted that several studies have conducted analyses related to the epidemiology of injuries to badminton athletes from various levels of play (professional and recreational) [5-7]. Experts believe that by mapping related factors, and the impact of injury, it can later be used for coaches or athletes themselves in reducing the risk of injury in badminton [2-7].

Several previous studies have revealed that injuries in badminton are caused by the characteristics of the explosive movement required to play it which forces badminton players to make such movements quickly from 
one position to another [8]. More specifically, some experts have revealed that this explosive movement causes asymmetry and dysfunctions in some parts of the body due to inadequacies in segment or joint areas when performing the explosive movement [9]. Due to this fact, it is not surprising that even though badminton is a non-contact sport, the risk of injury in this sport still has to be taken into account.

There have been many epidemiological studies of injuries in badminton athletes [2-7, 10-12]. Experts believe that analyzing badminton injuries will help coaches and athletes to reduce the risk of injury to badminton athletes. For example, Yung et al. [10] reported that the Injury Rate (IR) (1000 hours) in 44 elite badminton players in Hong Kong was 5.04 from calculations based on team records. Furthermore, several clinical analyses of injuries revealed that badminton injuries generally occur in the lower limb, with more than $58 \%$ of cases in that area [11]. Interestingly, ACL injuries are particularly common, making up $37 \%$ of all injuries, according to Uchiyama, et al. [12].

On the other hand, it should be realized that some facts about epidemiological studies of the badminton injuries described above are specific to elite level athletes, and it is very rare to find epidemiological studies of badminton injuries at the recreational level. This is very reasonable, considering that studies generally only focus on elite level athletes, assuming that elite level athletes are more likely to be injured, given the characteristics of higher-intensity matches. Unfortunately, at this time, an epidemiological study is also required at the recreational level of badminton, considering that this sport has begun to develop quite rapidly.

Additionally, previous studies on badminton injuries have revealed that recreational badminton athletes experience higher plantar loading in the lateral forefoot but lower loading in the medial forefoot compared to skilled athletes, thus leading to a higher risk of knee injury in recreational players compared to elite level athletes [13]. Due to these assumptions and findings, it can be said that the risk of injury to recreational players is higher than that of professional players, due to a lack of inappropriate techniques. Therefore, the purpose of this study is to find out and describe the types of injuries sustained by recreational badminton players in Indonesia.

\section{Materials and Methods}

In a descriptive study, conducted by interview in this study, we evaluated recreational male badminton players $(\mathrm{n}=80)$ at Rawamangun Jakarta Sports Center. Before starting the interview process, we explained the purpose and benefits of this study to each participant. After all participants had received an explanation about this study, they were asked to sign an informed consent form signifying that they were willing to participate in this interview. This study passed the ethics committee test issued by The Ethics Committee of Jakarta State University (392/UN39.16/PR.07/2020). It took place from 1st February 2020 to 1st March 2020.

\subsection{Interview}

In this process, there were a total of five $(n=5)$ interviewers, where each interviewer conducts interviews with individual participants. All reviewers had received training in the familiarization session, as well as a summary of the questions that had to be asked to the participants. The focus of the interview questions is divided into 2 sessions, namely the general session, which involves questions about anthropometry data, years and frequency of playing badminton, medical history, and sports activities. In the general session, screening was conducted $(\mathrm{N}=100)$ related to the inclusion and exclusion criteria of the participants. The exclusion criteria are as follows: (1) players who play other sports, specifically contact-sports, (2) players who had previously suffered injuries outside of recreational badminton matches, (3) players who worked in occupations involving heavy manual work, (4) players who had participated in systematic badminton training, and (5) players aged under 20 years and over 50 years.

Furthermore, after screening based on the specified exclusion criteria, eighty $(n=80)$ participants were found who met the inclusion criteria in this study. Furthermore, participants were interviewed and had to answer several questions in the main interview section. In the main section of the interview, questions deal with the time of suffering an injury based on age, frequency of injury, type of injury, anatomy of the injury, and cause of injury. The questions refer to the results of a study conducted by Miyake et al. [14] stating that injury rates increase with age, the frequency of injuries is higher in matches, and the majority of the injury types are minor injuries. In addition, the questions on anatomy and the causes of injury refer to the review results of Phomsoupha \& Laffaye [15], showing that injuries occur in the eyes, arms and shoulders, the legs and back with their respective causes. The questions are presented in table 1 .

\section{Results}

From the hundred $(\mathrm{N}=100)$ participants, 20 were excluded, because 20 participants were included in the exclusion criteria (10 participants had experienced injuries outside of badminton, 5 participants had been involved in systematic badminton training, and 5 participants were active in contact sports). The results of anthropometry study showing years and frequency of playing badminton in a total of 80 recreational badminton players can be seen in Table 2. This table explains that the age range of the participants in this study is 21-50 years. In the age range of 21-30 years, the body mass index (BMI) is more ideal than 
in the age ranges of 31-40 years and 41-50 years. On the other hand, this study shows that as age increases, the frequency with which the participants play badminton decreases $(41-50$ years $=2.2 \pm 1.1$ vs $31-40$ years $=2.9 \pm$ 1.1 vs $21-30$ years $=3.1 \pm 0.8$ ).

On the question of age at first injury, this study produced surprising results where all age categories had an average age at first injury of $17.85 \pm 1.74$ years. On the other hand, this study shows that with increasing age, the average frequency of injuries suffered, both mild and severe in the span of one year, increases (41-50 years $=7.8 \pm 2.1$ vs $31-40$ years $=4.9 \pm 2.1$ vs $21-30$ years $=2.8 \pm 0.7$ ), as presented in Table 3. This survey shows that acute injury predominates in the age ranges of 21-30 years (83\%) and $31-40$ years $(53 \%)$. Meanwhile, at the age of $41-50$ years, overuse injury is the dominant injury compared to acute injury ( $83 \%$ vs $17 \%$ ). In terms of anatomical injuries, $74 \%$ of 80 participants had injuries to the lower limb, while only $26 \%$ of 80 participants had injuries to the upper limb. The results can be seen in more detail in Table 4.

This survey also shows the cause of severe injury (See Figure 1). In general, participants chose inadequate warm-up as a common reason for injury. This can be seen from $52.5 \%$ of the total 80 participants who chose inadequate warm-up as the cause of injury. More specifically, 12 participants from 18 in the age range of 21-30, 20 participants from 38 in the age range 31-40 years, and 10 participants from 24 in the age range $41-50$ years chose inadequate warm-up as the cause of injury.

Table 1. Questions related to injuries in recreational badminton players

\begin{tabular}{cl}
\hline No & \multicolumn{1}{c}{ Question } \\
\hline 1 & At what age did you first have a serious injury? \\
\hline 2 & How many times on average have you been injured lightly/severely in the span of one year? \\
\hline 3 & Was the injury an acute or overuse type of injury? \\
\hline 4 & What part of your body did you get seriously injured? \\
\hline 5 & What caused the severe injury according to the doctor's examination? \\
\hline
\end{tabular}

Table 2. Distribution of subjects grouped by age, anthropometry data, and badminton historical years and frequency of playing

\begin{tabular}{ccccccc}
\hline $\begin{array}{c}\text { Age range } \\
\text { (years) }\end{array}$ & $\begin{array}{c}\text { Number of } \\
\text { players }\end{array}$ & $\begin{array}{c}\text { Height } \\
\text { (meters) }\end{array}$ & $\begin{array}{c}\text { Weight } \\
\mathbf{( K g )}\end{array}$ & $\begin{array}{c}\mathbf{B M I} \\
\left.\mathbf{( K g} / \mathbf{m}^{2}\right)\end{array}$ & $\begin{array}{c}\text { Years of playing } \\
\text { badminton } \\
\text { (years) }\end{array}$ & $\begin{array}{c}\text { Frequency of } \\
\text { playing badminton } \\
\text { (Per week) }\end{array}$ \\
\hline $21-30$ & 18 & $166.8 \pm 8.9$ & $68.41 \pm 11.2$ & $24.4 \pm 2.3$ & $6.1 \pm 1.4$ & $3.1 \pm 0.8$ \\
$31-40$ & 38 & $166.3 \pm 8.3$ & $75.69 \pm 8.1$ & $27.5 \pm 3.1$ & $11.4 \pm 3.5$ & $2.9 \pm 1.1$ \\
$41-50$ & 24 & $159.8 \pm 6.8$ & $68.84 \pm 12.8$ & $27.2 \pm 5.9$ & $14.3 \pm 2.5$ & $2.2 \pm 1.1$ \\
\hline
\end{tabular}

Table 3. Distribution of age at first injury and mean injury in one year

\begin{tabular}{ccc}
\hline $\begin{array}{c}\text { Age range } \\
\text { (years) }\end{array}$ & $\begin{array}{c}\text { First age injured } \\
\text { (years) }\end{array}$ & $\begin{array}{c}\text { Average of minor/severe injuries in one year } \\
\text { (frequency) }\end{array}$ \\
\hline $21-30$ & $18.1 \pm 1.4$ & $2.8 \pm 0.7$ \\
$31-40$ & $17.2 \pm 1.8$ & $4.9 \pm 2.1$ \\
$41-50$ & $18.8 \pm 1.5$ & $7.8 \pm 2.1$ \\
\hline
\end{tabular}

Table 4. Distribution of injury classification and anatomical injuries

\begin{tabular}{ccccc}
\hline \multirow{2}{*}{$\begin{array}{c}\text { Age range } \\
\text { (years) }\end{array}$} & \multicolumn{2}{c}{ Injury Classification } & \multicolumn{2}{c}{ Anatomical Injuries } \\
\cline { 2 - 5 } & $\begin{array}{c}\text { Acute } \\
\text { (Number of players) }\end{array}$ & $\begin{array}{c}\text { Overuse } \\
\text { (Number of players) }\end{array}$ & $\begin{array}{c}\text { Lower Limb } \\
\text { (Number of players) }\end{array}$ & $\begin{array}{c}\text { Upper Limb } \\
\text { (Number of players) }\end{array}$ \\
\hline $21-30$ & 15 & 3 & 14 & 4 \\
$31-40$ & 20 & 18 & 30 & 8 \\
$41-50$ & 4 & 20 & 15 & 9 \\
\hline
\end{tabular}




\section{Common Reasons for Injuries in 21 - 30 Years}

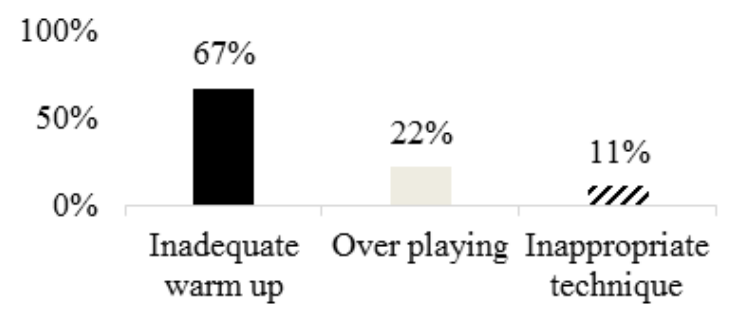

\section{Common Reasons for Injuries in 31 - 40 Years}

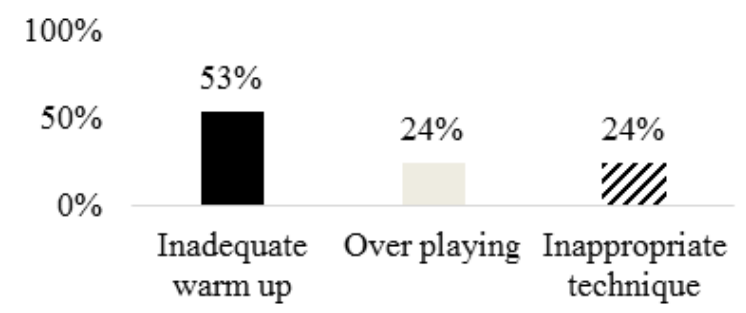

\section{Common Reasons for Injuries in 41 - 50 Years}

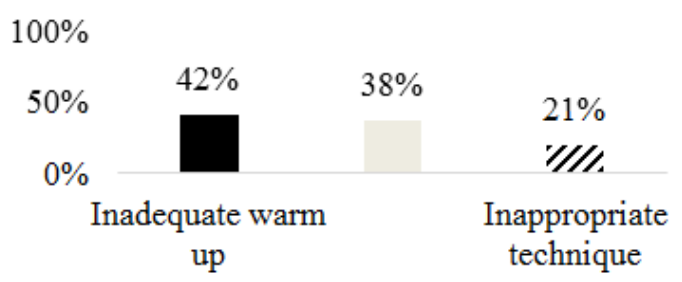

Figure 1. Distribution percentage of common reason for injuries in badminton

\section{Discussion}

This study aimed to determine and describe the types of injuries sustained by recreational badminton players in Indonesia. In accordance with this objective, this study succeeded in revealing several facts about injuries to recreational badminton players in Indonesia. Some of the facts obtained in this study are: (1) as people get older, the risk of injury in recreational badminton players in Indonesia increases, (2) the average age of first experiencing an injury is $17.85 \pm 1.74$ years, (3) the lower limb is the body part that is most frequently injured, and (4) inadequate warm-up is a common cause of injury.

Based on these results, this study supports several previous studies which have also found that the lower limb is the part of the body that is often injured. For example, Goh et al. [15] confirmed that the lower limb is the most frequently injured body part in badminton players, $71.4 \%$ of the 63 participants admitted to having an injury to the lower limb, with the knee being the area most frequently injured. Although the study conducted by Goh et al. [15] is a survey of professional players, the similarity in the results of this study makes it possible to assume that there is a similar risk of injury to the lower limb in both recreational players and professional players.

Other studies that also support the findings of this study are the survey study conducted by Muttalib et al. [16] which revealed the results that inadequate warm-up is a common cause of injury. The similarity of these findings is in line with the results of this study, where we stated that $52.5 \%$ of the total 80 participants chose inadequate warm-up as the cause of injury. Inadequate warm-up is considered to be the main factor that causes an injury, which seems very reasonable considering a previous study conducted by Woods et al. [17] which revealed that if warm-ups are not carried out properly, muscle flexibility will be disrupted when performing a sporting movement, and the impact is that the muscles will not be ready to meet the needs of the movement, thus increasing the risk of injury.

The most interesting finding in this study is that we succeeded in revealing that on average the older you get, the higher the risk of injury. This may be the most promising novelty in this study, considering that, to the best of the authors' knowledge, there are no studies that reveal the frequency of injuries between age ranges. Additionally, the statement that the older you get, the higher your risk of injury seems to be in line with some previous literature which revealed that as you age, your muscle movement ability and flexibility decreases, thus increasing the risk of injury [18].

In the end, this study is expected to be an additional document that can help prevent injurious actions in recreational badminton. We are aware that there are several shortcomings in this study, such as (1) we did not measure injury surveys for female recreational badminton players, (2) we did not use a severity indicator scale for injuries, such as the Visual Analog Scale (VAS), which can determine the extent of severity of injuries sustained. Some of these limitations are expected to be answered by several further studies so that they can complement the findings obtained in this study. 


\section{Conclusions}

This study showed that as people get older, the risk of injury in recreational badminton players in Indonesia increases. Inadequate warm-up is a common cause of injury risk for all ages. And the lower limb is the part of the body that is often injured. This study encourages recreational badminton players to pay more attention to the warm-up process in order to reduce the risk of injury.

\section{REFERENCES}

[1] Apriantono T., Herman I., Winata B., Hidayat II., Hasan MF., Juniarsyah AD., Ihsani SI, "Physiological Characteristics of Indonesian Junior Badminton Players: Men's Double Category," International Journal of Human Movement and Sports Sciences, vol. 8 (6), pp. 444-454, 2020. DOI: $10.13189 /$ saj.2020.080617.

[2] Marchena-Rodriguez A., Gijon-Nogueron G., Cabello-Manrique D., Ortega-Avila AB, "Incidence of injuries among amateur badminton players: A cross-sectional study," Medicine, vol. 99 (18), e19785, 2020. DOI: 10.1097/MD.0000000000019785.

[3] Høy K., Lindblad BE., Terkelsen CJ., Helleland HE., Terkelsen CJ, "Badminton injuries--a prospective epidemiological and socioeconomic study," British journal of sports medicine, vol. 28,(4), pp. 276-9, 1994 DOI: 10.1136/bjsm.28.4.276.

[4] Nhan DT, Klyce W, Lee RJ, "Epidemiological Patterns of Alternative Racquet-Sport Injuries in the United States, 1997-2016," Orthopaedic journal of sports medicine, vol. 6 (7), 2325967118786237, 2018, DOI: 10.1177/2325967118 786237.

[5] Iwamoto J., Takeda T., Sato Y., Matsumoto H, "Retrospective case evaluation of gender differences in sports injuries in a Japanese sports medicine clinic," Gender medicine, vol. 5 (4), pp. 405-14, 2008. DOI: 10.1016/j.genm.2008.10.002.

[6] Pardiwala DN., Subbiah K., Rao N., Modi R, "Badminton Injuries in Elite Athletes: A Review of Epidemiology and Biomechanics," Indian journal of orthopaedics, vol. 54 (3), pp. 237-245, 2020, DOI: 10.1007/s43465-020-00054-1.

[7] Couppé C., Thorborg K., Hansen M., Fahlström M., Bjordal JM., Nielsen D., Baun M., Storgaard M., Magnusson SP, "Shoulder rotational profiles in young healthy elite female and male badminton players," Scandinavian journal of medicine \& science in sports, vol. 24 (1), pp. 122-8, 2014. DOI: 10.1111/j.1600-0838.2012.01480.x.

[8] Zhang Z., Li S., Wan B., Visentin P.., Jiang Q, Dyck M., Li H, Shan G, "The Influence of X-Factor (Trunk Rotation) and Experience on the Quality of the Badminton Forehand
Smash,” Journal of human kinetics, vol. 53, pp. 9-22, 2016. DOI: 10.1515/hukin-2016-0006.

[9] Jang HS., Kim D., Park J, "Immediate effects of different types of stretching exercises on badminton jump smash," The Journal of sports medicine and physical fitness, vol. 58, pp. 7-8, 2018. DOI: 10.23736/S0022-4707.17.06989-4.

[10] Yung PS., Chan RH., Wong FC., Cheuk PW., Fong DT, "Epidemiology of injuries in Hong Kong elite badminton athletes," Research in sports medicine (Print), vol. 15 (2), pp. 133-146, 2007 DOI: 10.1080/15438620701405263.

[11] Jørgensen, U, and S Winge, "Epidemiology of badminton injuries," International journal of sports medicine, vol. 8 (6), pp. 379-382, 1987. DOI: 10.1055/s-2008-1025689.

[12] Uchiyama E., Suzuki H., Ikegami Y., Nakamura Y., Taketomi S., Kawaguchi K., Mizutani Y., Doi T, "Muscles Cooperation Analysis Using Akaike Information Criteria for Anterior Cruciate Ligament," Injury Prevention. Annu Int Conf IEEE Eng Med Biol Soc, pp. 4799-4802, 2020. DOI: $\quad 10.1109 / \mathrm{EMBC} 44109.2020 .9175811 . \quad$ PMID: 33019064 .

[13] Mei Q., Gu Y., Fu F., Fernandez J, "A biomechanical investigation of right-forward lunging step among badminton players," Journal of sports sciences, vol. 35 (5), pp. 457-462, 2017.2 DOI: 10.1080/02640414.2016.1172723.

[14] Miyake E., Yatsunami M., Kurabayashi J., Teruya K., Sekine Y., Endo T., Nishida R., Takano N., Sato S., Jae Kyung H, "A Prospective Epidemiological Study of Injuries in Japanese National Tournament-Level Badminton Players From Junior High School to University," Asian journal of sports medicine, vol. 7 (1), e29637, 2016. DOI: 10.5812/asjsm.29637.

[15] Phomsoupha, M., \& Laffaye, G. (2020). Injuries in badminton: a review. Science \& Sports, 35(4), 189-199.

[16] Goh SL., Mokhtar AH., Mohamad Ali MR, "Badminton injuries in youth competitive players," The Journal of sports medicine and physical fitness, vol. 53 (1), pp. 65-70, 2013.

[17] Muttalib A., Ortho MS., Zaidi M., Khoo C, "A Survey on Common Injuries in Recreational Badminton Players," Malaysian Orthopaedic Journal, Vol 3, pp. 8-11, 2009. DOI: 10.5704/MOJ.0911.002.

[18] Woods K., Bishop P., Jones E, "Warm-up and stretching in the prevention of muscular injury," Sports medicine (Auckland, N.Z.), vol. 37 (12), pp. 1089-1099, 2007. DOI: 10.2165/00007256-200737120-00006.

[19] Lopes TJA., Simic M., Alves DS., Bunn PDS., Rodrigues AI., Terra BS., Lima MDS., Ribeiro FM., Vilão P., Pappas E, "Physical Performance Measures of Flexibility, Hip Strength, Lower Limb Power, and Trunk Endurance in Healthy Navy Cadets: Normative Data and Differences Between Sex and Limb Dominance," Journal of strength and conditioning research, vol. 35 (2), pp. 458-464, 2021. DOI: $10.1519 /$ JSC.0000000000002365 